\title{
RETÓRICA E ARQUITETURA COLONIAL LUSO-BRASILEIRA NO SÉCULO XVIII ${ }^{1}$
}

Rodrigo Almeida Bastos ${ }^{2}$

\section{Resumo}

O texto desenvolve a importância que a pesquisa dos procedimentos e princípios retóricos coevos tem para o estudo da arte, da arquitetura e das nossas cidades de origem colonial. Procurar compreendê-las através desses princípios e procedimentos pode nos levar a uma compreensão mais verossímil da história da arte luso-brasileira, além de permitir uma revisão crítica de muitos paradigmas que ainda persistem na historiografia, como "espontaneidade", "originalidade", "autonomia", "identidade nacional", "evolução" dos estilos etc.

Palavras-chave: Retórica, Arquitetura colonial, Historiografia.

\begin{abstract}
This paper shows the importance of rhetoric precepts and methods research for the comprehension of art, architecture and colonial cities. This way can lead us to a very important history, more verisimilar than what moderns and anachronic categories, like "spontaneity", "originality", "autonomy", "national identity", "styling evolution" etc. could suggest.
\end{abstract}

Key-words: Rhetoric, Colonial Architecture, Historiography.

No diálogo denominado Górgias, um dos primeiros textos em que se discutiu se a Retórica seria ou não uma arte (téchne), Platão apresentou aquela que seria uma de suas mais polêmicas diatribes. Orientada à eloqüência e à persuasão, a Retórica não conduz necessariamente ao bem e à verdade, e só deve ser utilizada, pois, se estiver "à serviço da justiça" ". Assim como em outros diálogos - no Fedro, por exemplo -, Platão rechaçou o uso da Retórica em nome da Filosofia, num contexto político em que a oratória e a sofística, desobrigadas da procura pela "verdade", poderiam desviar os cidadãos e os destinos da república de caminhos virtuosos.

Retórica e justiça. Recorro a esta breve referência ao texto antigo não apenas porque ele oficialmente inaugura, por assim dizer, a inextinguível polêmica da retórica como arte e seus limites éticos, mas também porque evoca um dos núcleos centrais que justificaram e legitimaram os usos e as finalidades da arte religiosa produzida na América portuguesa durante os séculos XVII e XVIII. Nesse período, correspondente à reafirmação católica frente aos ataques da reforma protestante, o que se produziu em arte nos ambientes católicos estava, sim, retoricamente movido por um sentido de justiça. Praticamente tudo o que se fabricou e se construiu nesse contexto visava à continuação do projeto divino e à celebração de fé numa justiça tanto benevolente quanto implacável;

\footnotetext{
1 Este texto resulta da atual pesquisa de Doutorado em História e Fundamentos da Arquitetura e do Urbanismo pela FAU-USP, com o apoio da FAPESP (Fundação de Amparo à Pesquisa do Estado de São Paulo).

2 Faculdade de Arquitetura e Urbanismo da Universidade de São Paulo - FAUUSP (Doutorando)/ Cicognara. Engenheiro civil (UFG), arquiteto urbanista (UCG) e mestre em arquitetura e urbanismo pela UFMG. (e-mail:digobastos@gmail.com).

3 PLATÃO. Diálogos; Protágoras, Górgias, O Banquete, Fedão. Trad. de Carlos Alberto Nunes. Belém: UFPA, 1980. “Górgias”, p. 111-217, 527 c, p. 217.
} 
benevolente e misericordiosa em favor dos fiéis e convertidos, integrados ao corpo místico de Cristo e da Igreja Católica romana, assaz implacável contra os que dela se desviassem, descrentes ou heréticos, notadamente os protestantes. A arte religiosa correspondente à contra-reforma católica - imaginária, pintura, escultura, arquitetura, música, ornamentação, sermonística etc. - confluiu, toda ela, num discurso teológico-retórico de revelação de uma "verdade" de fé inquestionável em que estava implícita a justiça de Deus; uma justiça muito anterior e maior do que a passível de ser discernida pela razão ou pela filosofia dos homens, sob julgamento da qual seria sopesada, no dia do juízo, a salvação das almas.

Postulando a premissa de que seus objetivos eram análogos aos desígnios divinos, portanto justíssimos, a Igreja utilizou-se oportunamente da arte como instrumento de convencimento e reafirmação da instituição de fé católica. Desde a antiguidade, a arte retórica fornecera, conjuntamente à Poética, procedimentos e princípios formadores do pensamento e da produção artística ocidental, mas dessa vez um aspecto ressaltava-se particularmente favorável: o caráter "agonístico" da retórica e também da arte em questão. Como destacaram Plebe e Emanuele, na retórica "é essencial o critério de ter êxito, de ser eficaz". . E em se tratando do conluio essencial entre arte e retórica, da relação histórica tradicional entre elas, é na arte contra-reformista que se coaduna, mais incisivamente do que em qualquer outro momento da história, a necessidade da arte desempenhar um êxito cuja motivação não é específica ou exclusiva de seu próprio campo. Não estou falando unicamente da eficácia verossímil da representação ou do êxito técnico referente à criação dos efeitos adequados, qualidades especificamente artísticas, mas do êxito, sobretudo, que tais efeitos artificiosos teriam em evidenciar, ou seja, em colocar diante dos olhos dos fiéis, o esplendor misterioso de Deus e a legitimidade institucional da Igreja católica em sua missão ancestral de pastorear os homens rumo à salvação proveniente da palavra divina.

Materializada de várias formas como discurso de representação do Verbum Dei das sagradas escrituras e da própria encarnação metafórica do "Verbo" em Seu filho Jesus Cristo - a arte contra-reformista teve, em sua base, uma finalidade político-teológica, cuja eficácia procurava garantir a adesão corporativa e a admiração maravilhosa pela verdade de fé transmitida pela Igreja e pelos estados católicos. E não se tratavam de dois propósitos distintos, depositados sob a responsabilidade da mesma arte, um: a revelação de Deus, outro: a vitória sobre os protestantes. A vitória contra estes seria entendida como um "bem", uma vitória mesma da "justiça" e da "verdade" divinas continuamente reveladas na história. No centro da discussão, como se pode perceber, a palavra, o discurso, e a necessidade de evidenciação artística - material - da verdade e do mistério. Nada mais justificável, então, à retórica das artes, do que servir ao Preceptor primeiro, imitando-o na arte mesma dedicada à Sua própria revelação. Segundo a tradição aristotélico-estóica, reinterpretada pelos patronos e seguidores da escolástica, é através da razão, faculdade "divina", que o homem é capaz de contemplar a natureza e discernir o que é a ordem e demais preceitos dignos de imitação - beleza, harmonia, proporção, simetria, formosura, consonância, unidade, esplendor, decoro, a lei suprema da conveniência etc. - estendidos ao pensamento e à produção da arte. Não mais diretamente dependente da imitação da natureza como modelo divino de criação, mas na propriedade maravilhosa do artifício orientado pela luz da graça inata que Deus engendra nos homens agudos e engenhosos, a

\footnotetext{
4 PLEBE, Armando; EMANUElLE, Pietro. Manual de Retórica. Trad. de Eduardo Brandão. São Paulo: Martins Fontes, 1992, p. 12.
} 
arte religiosa revoltava então à sua Causa primeira e também Fim. ${ }^{5}$ A "agudeza de engenho", escreveu Tesauro na introdução de "A Luneta Aristotélica" (Il cannocchiale aristotelico, 1670), é um "vestígio da divindade na alma humana". O artista é como que um instrumento; e os homens que seguem retamente o caminho de Deus artificiam em prol do projeto divino ${ }^{7}$, interessando pensar que é muito decoroso usar os preceitos divinos para artificiar em Seu nome. O tempo e a história são dimensões nas quais se realiza uma "Ordem eterna", "fundada na verdade e na justiça", e a "missão do homem" é identificarse com esta vontade de Deus realizando-a na terra, conformando-se com a "lei eterna" e aspirando realizar ao menos "parte" da "ordem" divinamente estabelecida".

Neste contexto está inserida a arte produzida na América portuguesa durante o século XVIII. Portugal foi um dos Estados monárquicos mais afinados à política do Vaticano, além de propagar e expandir a religião católica aos confins do Oriente e da América havia pouco descoberta, numa espécie de missão divina assimilada pelos reis portugueses. Conhecer essa arte, portanto, a partir dos procedimentos e preceitos teológico-retóricos, preceitos exatamente coevos à formação dos conjuntos arquitetônicos e urbanos, se coloca como tarefa muito interessante e necessária à historiografia. Além disso, a reconstituição histórica dos objetos e também dos conceitos e princípios coevos pode tornar relativa a supremacia, ainda prevalente, das categorias modernas que foram utilizadas para reconstruir historicamente esses objetos durante o século XX e mesmo antes, e que contam, anacronicamente, muito mais sobre as ideologias dos escritores do que dos objetos em si. Essa é a tese que vem defendendo há anos o professor João Adolfo Hansen (FFLCH-USP), trabalhado na compreensão das belas letras luso-brasileiras; uma postura que oferece aberturas de uma verdadeira revisão historiográfica que pode ser muito útil à História da arte brasileira em geral, da arquitetura e do urbanismo coloniais, uma vez que com ela se busca também recuperar historicamente as teorias e preceitos que sustentavam literalmente, naqueles tempos, a concepção, a produção e a recepção das artes. É nesse caminho que venho pesquisando e repensando a história da arte na capitania de Minas Gerais no século XVIII, a partir dos procedimentos e preceitos retóricos e teológicos, extensamente presentes na documentação primária e nos tratados artísticos e teológicos vigentes no período. Muito resumidamente, pelo pouco tempo que aqui disponho, apresento-lhes algumas aberturas vislumbradas para a leitura do discurso teológico-retórico da arquitetura e da cidade colonial.

Em se tratando da república monárquica católica, era a cidade a sua parte mais importante. Como expôs Francisco Suarez, um dos principais teólogos da chamada neoescolástica, pensamento que regulou a teologia política das monarquias católicas contrareformistas, a cidade era o lugar por excelência da manifestação da cultura e da ordem, onde se deveria encontrar não apenas a comodidade física necessária à vida em sociedade mas também o aprimoramento do espírito humano'. Compreendida como parte hierarquicamente integrada ao corpo místico-político do reino, a cidade deveria representar a dignidade e a decência da República, como reafirmação permanente e incontestável dos

\footnotetext{
5 Cf. HANSEN, João Adolfo. Artes seiscentistas e teologia política. In: TIRAPELI, Percival (Org.). Arte sacra colonial: barroco memória viva. São Paulo: UNESP/Imprensa Oficial do Estado, 2001. p. 180-189.

6 TESAURO, Emanuele. Il Cannocchiale aristotelico. Berlin/Zurich: Verlag Gehlen - Bad Homburg, 1968. Dell'Argutezza et de'svoi parti, p. A. (Fac-símile da edição de 1670, Torino).(grifos do autor).

${ }^{7}$ Cf. ROCAFULL, Jose M. Gallegos. La doctrina politica del P. Francisco Suarez. México: Editorial Jus, 1948.

8 ROCAFULL, op. cit., p. 14-15; 172.

${ }^{9}$ ROCAFFUL, op. cit., p. 89.
} 
pressupostos e princípios que regulavam a justiça e conservavam a ordem e o pacto colonial. Como o fundamento da república era sagrado, já que esta era um elo integrante da cadeia divina de hierarquias e instituições fundadas pelo homem para conservar a fé e a caridade, o decoro e a decência do sagrado se tornaram aspectos imprescindíveis a serem proporcionados e evidenciados pelo discurso teológico-retórico da cidade colonial.

Assim, não foram poucas as requisições de conveniência, decoro e decência que encontrei nos documentos primários relativos à implantação de povoações em Minas Gerais no século XVIII. E aparecem nas quatro empresas que identifico como sistemáticas à sua implantação: Eleição, Adequação, Aumento e Conservação: 1) Eleição on invenção do sitio de implantação, 2) Adequação das novas estruturas ao sitio e estruturas construidas preexistentes, 3) Aumento da povoação, e, 4) Conservação da povoação e de suas várias partes. Identifiquei-as enquanto pesquisava o "decoro" na implantação de novas povoações em Minas Gerais na primeira metade do século XVIII - tema de minha dissertação de mestrado ${ }^{10}$. Os termos de ereção de vilas no início do século XVIII fazem costumeira referência à necessidade de "conveniência", "capacidade" e "comodidade" dos sítios escolhidos para implantação de uma povoação, uma escolha prudentemente ajuizada pelo governador da capitania, em "Junta Geral" formada também por "representantes dos moradores". Depois de ereta a vila e instalada a câmara, iniciava-se um processo de acomodação da povoação regulada por vários preceitos e procedimentos concentrados principalmente nas atividades dos juízes e vereadores das câmaras:

1) Adequação das novas estruturas ao sítio e estruturas construidas preexistentes: concessão de aforamentos sobre propriedades já estabelecidas por moradores; "licenças" para "reforma", reconstrução e "retificação" de casas mais "decentes" e "seguras", com materiais mais dignos, como o barro e a telha, em substituição à palha; "endireitamento" e realinhamento de arruamentos, a fim de assegurar a "decência" da povoação; eventualmente construções ou "partes" destas deveriam ser "demolidas" para se atingir principalmente continuidade nos alinhamentos das vias, em nome da "conveniência" pública e da "formosura" da povoação;

2) "Aumento" da povoação. No âmbito edilício, o termo "aumento", também freqüente na documentação primária coeva, significava, naquele tempo, tanto expansão física como "acrescentamento"11 de "dignidade", assegurada através de: abertura de "praças" e novos "arruamentos" melhor "alinhados" e "decentes", concessão de novos aforamentos para edificação de novas casas, construção de novos edifícios públicos, câmara e cadeia, chafarizes e pontes; construção "ornada" de capelas leigas e igrejas paroquiais, consolidação de largos e praças;

3) "Conservação" da povoação e de suas várias "partes": "reformas", "reparos" e "correições" urbanas parcelares, ou seja, em "partes" da povoação, públicas e particulares, que visavam a manutenção "conveniente" da sua estrutura física e a "correção" de sua aparência; manutenção da "comodidade", da "decência" aparente, da "limpeza" e do "asseio" da povoação.

Esses processos povoadores complementavam-se, simultaneamente, empenhados por agentes que operavam por procedimentos e princípios validados por longa tradição artístico-construtiva. Enquanto abriam-se novos arruamentos, outros eram realinhados. Não sendo possível arruar retilineamente, que se mantivessem pelo menos contínuos os alinhamentos; novos aforamentos eram concedidos a moradores enquanto outros

${ }^{10}$ BASTOS, Rodrigo Almeida. A Arte do Urbanismo Conveniente: o decoro na implantação de novas povoações em Minas Gerais na primeira metade do século XVIII. Dissertação (Mestrado em Arquitetura e Urbanismo)Escola de Arquitetura, UFMG, Belo Horizonte, 2003.

${ }^{11}$ Cf. BLUTEAU. op. cit. Augmentar; Augmento. v. 1. p. 670. 
licenciavam reformas de suas casas, cobrindo-as "de telha", material mais digno e decente do que a palha. A conveniente eleição do sítio, o aumento e a conservação da povoação representavam a permanência e a dignidade da república; assim como a crescente inserção de "ornatos", como os chafarizes e as próprias igrejas e capelas, ornatos todos do grande discurso, simultaneamente útil e deleitoso, da cidade.

Vários eram os agentes luso-brasileiros responsáveis por esses processos povoadores: vereadores, juízes ordinários e juízes de ofícios, ouvidores, corregedores, governadores, engenheiros militares, mestres, oficiais, artistas e artesãos, procuradores dos moradores e das irmandades, conselheiros e secretários do Conselho Ultramarino, eventualmente o próprio rei e prelados. Dentre os procedimentos: a arrematação e a aceitação das obras, a redação das "condições" e "apontamentos", que consistiam em verdadeiros projetos discursivos, nos quais se encontram medidas, proporções, designações estilísticas, referência a modelos miméticos, materiais e técnicas construtivas competentes à execução da obra; as "medições" e "louvações", com as quais se aferia a "conformidade ao risco" e a "competência" de execução, necessárias à aceitação das obras arrematadas pelos construtores; as "correições", realizadas tanto por vereadores e juízes a respeito da coisa pública (res publica) edificada, arruamentos e construções aparentes, quanto também pelos mestres de ofícios (geralmente "louvados") a respeito de obras particulares como as realizadas em igrejas de irmandades e edifícios oficiais como as casas de câmara e palácios de governadores; as "vistorias", feitas por esses mesmos agentes ordinários e também por "visitadores" que chegavam da metrópole, corregedores e ouvidores - objetivando a escolha de sítios para edifícios públicos, aberturas de novos arruamentos e praças, providências para "limpeza" e "asseio" de becos e arruamentos; "ajustes", que visavam várias retificações, referentes a preços de contratos e também às próprias obras que mereciam "correções" e "ajustes" em suas execuções. Dentre os princípios, alguns de antiqüíssima tradição retórico-poética: "conveniência", "decência", "conformidade", "decoro", "perfeição", "formosura", "dignidade", "adequação", "elegância", "competência do ornamento", "proporção", "comodidade", "necessidade”, "asseio", "limpeza", "compostura", "engenho", "prudência", etc. Procedimentos e princípios bastante concernentes ao resguardo do decoro das edificações e da cidade como um todo composto de "partes" necessariamente integradas e representantes do decoro e da dignidade do corpo místico constituído do reino ${ }^{12}$.

A "comodidade" da povoação, por exemplo, bastante requerida nos documentos referentes à eleição dos sítios para implantação, constituía uma qualidade necessária ao conforto e usufruto dos habitantes, uma virtude imprescindível. Mais do que isso, a "comodidade" também desempenhava um papel representativo no discurso teológicoretórico da povoação. Assim, a "comodidade" dos vários "lugares", vilas e arraiais, enquanto satisfação proveitosa de proporções e usos, encarnava uma dignidade inerente à instituição genérica denominada "povoação", "parte" de um reino místico cujo fundamento, não esqueçamos, era sagrado". O "efeito" proveitoso advindo do uso

12 Cf. BASTOS, Rodrigo Almeida. O regime retórico da estrutura artístico-construtiva no Brasil-colônia. In: FURTADO, João Pinto; MORAES, Fernanda Borges de; BASTOS, Rodrigo Almeida. Fronteira, política $e$ urbaniz̧ação: a dinâmica de criação, crescimento e transformação dos espaços e caminhos do Brasil setecentista (Simpósio). 56 Reunião Anual da SBPC. SBPC/UFMT. Cuiabá, julho de 2004.

13 BASTOS, Rodrigo Almeida. A ordem sagrada da república colonial. In: Anais do III Seminário Interpretar Arquitetura. Belo Horizonte, EAUFMG, Nov./2005. 18 p. (No prelo). (Estará disponível no número "9" da revista eletrônica: www.arq.ufmg.br/ia). 
ordinário e satisfatório das comodidades urbanas e dos caminhos encenava, então, um discurso bastante verossímil, recebido pela comunidade colonial como uma virtude, uma dignidade urbana. O efeito proveitoso da comodidade evidenciava, retoricamente, a aptidão da República monárquica católica em proporcionar o "bem comum" e a satisfação ordinária das necessidades humanas. É interessante pensar, então, que a arquitetura e a cidade colonial, em seus léxicos retóricos específicos, irredutíveis à palavra porquanto subordinados ao domínio simultâneo do usufruto e da visão afetuosa, materializavam conceitos e virtudes que funcionavam como argumentos retóricos capazes de colaborar com a adesão colonial à condução política metropolitana e à ordem estabelecida pelos homens em nome de um projeto maior advogado como continuação do divino. Bastante interessante, aqui, é o caso de Vila Rica de Ouro Preto, que ilustra tanto a pertinência das regras quanto também o juízo e a prudência dos agentes responsáveis pelas resoluções construtivas. Quando da eleição do sítio para implantação da vila, em julho de 1711, o governador, Antonio de Albuquerque Coelho de Carvalho, alertou que "não achava o sítio muito acomodado", mas acabou cedendo às requisições dos moradores de erigirem ali mesmo a vila, na união dos dois arraiais de Antônio Dias e Nossa Senhora do Pilar, tendo ao centro o Morro de Santa Quitéria, pois aquele era, apesar de incômodo, o "sítio de maiores conveniências que os povos tinham achado para o comércio". ${ }^{14}$ Ainda hoje admiramos a implantação da cidade no acidentado sítio de Ouro Preto, resultado, entre tantos fatores, da consideração de um juízo prudente e decoroso relativo às conveniências éticas dos moradores, em uma circunstância física concreta de proporções pouco favoráveis. Pouco acomodado à vida ordinária mas muito conveniente ao "comércio" dos moradores, o sítio se apresentou também maravilhosamente adequado, durante o processo de formação da povoação, para a decente e engenhosa implantação de templos elevados, igrejas e capelas, que ascenderam numerosos, alguns graciosamente majestosos, sobre cumes e ombreiras de morros, consolidando a cidade de Ouro Preto como um dos sítios urbanos coloniais mais ornados, eloqüentes e característicos da arte e da teologia política luso-brasileira setecentista.

A invenção ou escolha dos sítios para implantação de capelas em Minas Gerais no século XVIII considerava, via de regra, as recomendações das Constituições Primeiras do Arcebispado da Babia, ordenadas em 1707 pelo arcebispo da Bahia Sebastião Monteiro da Vide $^{15}$. Os templos deveriam ser implantados em lugares "elevados", "cômodos" e "decentes", resguardados com "asseio" e "limpeza", livres de qualquer "umidade" ou "imundície"16. Neste assunto, as Constituições Primeiras seguem muito proximamente as recomendações do tratado do Bispo de Milão e "protetor de Portugal", São Carlos Borromeu, sobre a arte religiosa (Instructionum Fabricae et supellectilis ecclesiasticae, 1577). Além de destacarem os templos - quase sempre livres do contato com outras edificações para permitir que se deambulasse em torno delas em procissão - acentuando os efeitos de perspectiva e majestade religiosa, os sítios evidenciam hierarquicamente a eminente posição dos estamentos e as proporções que regulavam a ordem teológico-política colonial. A invenção dos oragos, as alegorias e figuras que ornamentam as fachadas, portadas e altares obedeciam também, como de costume, a "regra" da conveniência e do decoro, devendo apresentar figuras apropriadas ao tema do edifício e sua destinação, compondo-se com

${ }^{14} \mathrm{APM}$ SC 06, f. 20, 20v, 21. “Termo da erecçao de Va Rica”. Vila Rica, 08/07/1711.

15 CONSTITUIÇÕES primeiras do arcebispado da Babia (1707). São Paulo: Tipographia 2 de Dezembro/Antonio Louzada Antunes, 1853.

${ }^{16}$ Cf. CONSTITUIÇÕE, L.4, XVII, “Da Edificação, e reparação das Igrejas Parochiaes”, \ 687-689, p. 252-3. 
decência e majestade dignas do sagrado, capazes de aumentá-lo em magnificência, ornato e esplendor.

É preciso lembrar que a produção artística era pensada nesse tempo em virtude de sua utilidade ${ }^{17}$. A moderna autonomia da arte, aqui, é muito estranha. Os artistas, artesãos e artífices coloniais luso-brasileiros não criavam para contribuir com a História da arte, tampouco para serem alvos de um juízo estético autônomo, como as categorias modernas anacrônicas acabam induzindo. A beleza era uma reunião de conveniências poética e retoricamente concordadas, conveniências políticas, teológicas, de gênero, de assunto, de estilo, de recepção e utilização. A competência dos artistas ou dos artífices seria literalmente "louvada", ou seja, reconhecida por "louvados" e "mestres" do respectivo ofício eleitos anualmente pelos pares ou eventualmente pelas irmandades, se ele conseguisse acomodar engenhosamente as distintas circunstâncias envolvidas na concepção, produção e recepção da obra: a invenção dos riscos e modelos, a escolha dos materiais apropriados, dos lugares de implantação e disposição, os ornatos capazes de ultimar a elocução, afetar as paixões e criar os efeitos destinatários apropriados, tudo retórica e convenientemente medido pela recepção. As artes possuíam finalidades e destinações específicas, finalizando-se, por assim dizer, no fundamento mesmo que as justificava. Deus era a Causa primeira, e também o Fim, de todas as coisas, sobretudo nas monarquias católicas ibéricas. As artes setecentistas, a arquitetura e a cidade discursavam encenando, persuasória e permanentemente, o "theatrum sacrum"18 dos valores e propósitos católicos que fundamentavam a ética cristã contra-reformista.

Esse "teatro sacro" da cidade era desempenhado mais eloqüentemente pelos edifícios e lugares religiosos, obviamente. O tratadista português Matheus do Couto resumiu bem a importância dos templos para a retórica teológica de uma povoação: "a maior honra, autoridade, e grandeza, e ornato que um lugar tem é (sic) os templos" ${ }^{\text {"19. Se a }}$ decência da cidade deveria representar verossimilmente a dignidade da república, a decência da arquitetura religiosa mais ainda a representaria, lugar por excelência dedicado à manifestação do sagrado. Muitas são as discussões que consolidaram o preceito da decência como princípio hiperônimo da arte religiosa contra-reformista ${ }^{20}$, princípio que, pode-se constatar facilmente, domina explicitamente o elenco de preceptivas teológico-retóricas presentes na documentação primária setecentista relativa à fábrica artístico-construtiva religiosa e também às visitas pastorais que zelavam pela administração, conservação e aumento do patrimônio religioso dos bispados.

Compreender a fábrica artístico-construtiva na capitania de Minas Gerais no século XVIII a partir das teorias e princípios coevos convalidados por longa tradição tem permitido, além de rastrear melhor os processos de seu desenvolvimento, repudiar definitivamente o diagnóstico de "espontaneidade" aplicado às povoações mineiras durante praticamente todo o século XX. Concentro-me atualmente na arquitetura religiosa

\footnotetext{
${ }^{17}$ Cf. HANSEN, op. cit. p. 180.

18 Sobre o entendimento contra-reformista, de raiz jesuítica, das práticas de representação artística lusobrasileiras serem propostas como "Theatrum Sacrum" - encenação sagrada dos fundamentos católicos, cf. HANSEN, op. cit.

19 COUTO, Matheus do. Apud BUENO, Beatriz Piccolotto Siqueira. Desenho e desígnio: o Brasil dos engenheiros militares (1500-1822). Tese (Doutorado)-Faculdade de Arquitetura e Urbanismo, Universidade de São Paulo, São Paulo, 2001. p. 385.

${ }^{20}$ Cf. principalmente BLUNT, Anthony. O concílio de Trento e a arte religiosa. In: Teoria artística na Itália: 1450-1600. Tradução de João de Moura Jr. São Paulo: Cosac \& Naify, 2001. p. 142-181.
} 
setecentista, procurando compreender melhor os processos de sua produção, invenção, disposição e elocução, consciente de algumas circunstâncias que complexificam sobremaneira a análise dessa arquitetura, como por exemplo a descontinuidade temporal de suas construções e sobretudo a tradição historiográfica de cunho modernista que sempre apontou Minas Gerais setecentista como um celeiro de "gênios" "originais" que "evoluíram" inspirados por forças criativas telúricas singulares. É obvio que Minas Gerais foi singular em sua arte, arquitetura e urbanismo, assim como qualquer produção, em qualquer sítio, que tenha contemplado, por princípio - como era costume no século XVIII -, a conveniência e o decoro; uma orientação ético-retórica que justificava a necessidade de adaptação às várias circunstâncias éticas e poéticas envolvidas na concepção e na recepção das obras, os materiais e disponibilidades locais, os efeitos e finalidades perseguidas. Terá sido singular também não pelo "gênio" revoltoso de uma propalada "inconfidência" artística mineira, mas pela agudeza de "engenho" de seus artistas que os capacitou inventar com estilo, dispor e ornar segundo regras precisas e tradições antiqüíssimas, válidas por aqui até o princípio do século XIX e que compõem um sistema retórico muito estranho à nossa modernidade; um sistema que exige do pesquisador um mergulho exaustivo em um universo árduo porém fascinante, regido por racionalidades muitas vezes conflitantes com as categorias formais, os pressupostos e os corolários subjetivistas, dedutivos e evolucionistas daquilo que comumente chamamos de "barroco"; um universo teórico vastíssimo capaz de nos proporcionar, por certo, uma história mais verossímil dessas produções regidas não por identidades nacionais nem originalidades anacrônicas, mas por decoros e verossimilhanças.

Voltando, afinal, à referência introdutória sobre retórica e justiça, espero, além de ter deixado claro, logo no início, a pertinência em se falar de um sentido de justiça implícito à arte religiosa da reforma católica, ter deixado também claro a pertinência em se precisar falar de retórica quando o assunto é arte colonial e o gênero de discurso em questão é a Historiografia. Há alguns anos, ao recuperar a atualidade da Retórica de Aristóteles em contraposição à redução anti-positivista da História a uma retórica estilística do historiador, Carlo Ginzburg ${ }^{21}$ chamou a atenção para o fato de que o trabalho de juízes e historiadores é relativamente próximo, porque ambos estão sempre à procura de provas que proporcionem uma melhor e mais justa aproximação da "realidade", redundando numa conclusão que envolve, inexoravelmente, uma incisiva discussão sobre a metodologia da história. Reconhecer historicamente o regime retórico das artes seis e setecentistas lusobrasileiras, seus procedimentos e princípios, é, hoje, não só adequado como necessário, se pretende-se fazer justiça, também metodológica, aos objetos pensados e concebidos à luz dessa tradição.

\footnotetext{
${ }^{21}$ GINZBURG, Carlo. Relações de força; história, retórica, prova. Tradução de Jônatas Batista Neto. São Paulo: Companhia das Letras, 2002. Sobre Aristóteles e a história, mais uma vez. p. 47-63.
} 